\title{
Structural Reliability of Bridges Made with EAF Concretes
}

\author{
Mariano A. Zanini \\ Dept. of Civil, Environmental and Architectural Engineering, University of Padua, Via Marzolo 9, \\ 35131 Padua, Italy, marianoangelo.zanini@dicea.unipd.it
}

\begin{abstract}
The development of sustainable concretes is becoming an emerging issue in civil construction sector. The use of Electric Arc Furnace (EAF) slag aggregates in the production of concretes is one way to fulfill sustainability goals. Past research demonstrated a significant increase of mechanical properties of EAF concretes when compared with ones made with natural aggregates (NA); however, at the same time, their use implies also an increase of self-weight loads. The present contribution aims to investigate the reliability of structural systems realized with EAF concretes, with special emphasis to bridge structures. Two different bridge types, considered as case-study examples, are designed considering ordinary concrete mixes, and subsequently, a reliability analysis is run for each EAF concrete class in order to investigate the variation of structural safety margins related to the use of the sustainable EAF concretes in replacement to the ordinary NA concrete mix.
\end{abstract}

Keywords: EAF Slag, Reinforced Concrete, Structural Reliability, Bridges.

\section{Introduction}

Among the viable solutions to improve the environmental sustainability of cement-based materials, the use of recycled materials inside concrete mixes is acknowledged to be one of the most effective. Both non-conventional binders and aggregates can be successfully used to design concrete with satisfactorily high properties, both in terms of fresh properties, mechanical strength and durability. However, less research has been devoted both in laboratory and at fieldscale about other manufactured aggregate types, even if the use of some of them in concrete has shown promising results. This is the case of electric arc furnace (EAF) slag, a stony, very hard, heavy-weight crushed material, which has been successfully employed to produce concrete (Geiseler, 1996; Motz, and Geiseler, 2001; Koros, 2003). Further, many other studies (e.g. Papayanni and Anastasiou, 2010; Pellegrino et al., 2013; Faleschini et al., 2015; Santamaria et al., 2017) demonstrated how concrete with enhanced properties could be designed including EAF slag as partial or full aggregate replacement, significantly reducing the environmental impacts of the mix (Faleschini et al., 2014). Following the positive results achieved in smallscale specimens, some research works have been carried out to study also the structural behavior of full-scale structural elements made of reinforced concrete (RC), including EAF slag at varying replacement ratio inside the mixes (e.g. Pellegrino and Faleschini 2013; Faleschini et al., 2017a; Faleschini et al., 2017b; Faleschini et al., 2017c; De Domenico et al., 2018). The above literature has evidenced that EAF slag concrete can be suitably applied in gravity structures, where its heavy-weight and high strength result as positive features. However, doubts might arise about its efficacy when applied in elevation RC structures, because the enhanced mechanical strength might not sufficiently balance the increased dead loads of the RC EAF concrete elements. Accordingly, this paper aims to solve this question, analyzing three classes of EAF concrete, characterized by increasing aggregates replacement ratio, through reliability-based analyses of the capacity of RC structural elements made with EAFconcretes. 
Two different bridge types, i.e. a single-span simply supported prestressed reinforced concrete (PRC) bridge and a two- span continuous steel/concrete composite I-girder bridge, are designed according to the 2008- Italian Building Code prescriptions and considering a classic NA concrete mix. A reliability assessment is then performed for them, investigating the impact of full replacement of NA concrete with each of the three EAF concrete classes considered (i.e. $\mathrm{C} 1, \mathrm{C} 2, \mathrm{~A})$ on structural safety, thus quantifying the variation of structural safety margins related to the use of the sustainable EAF concretes in replacement to a classic NA concrete mix.

\section{Structural Reliability Index Assessment}

Figure 1 shows the general structural reliability workflow herein adopted in the following analyses: the workflow briefly presents key steps followed in assessing structural reliability index $\beta$. As regards the three EAF concrete classes, Table 1 lists main properties of the selected categories. More details can be found in Zanini (2019).

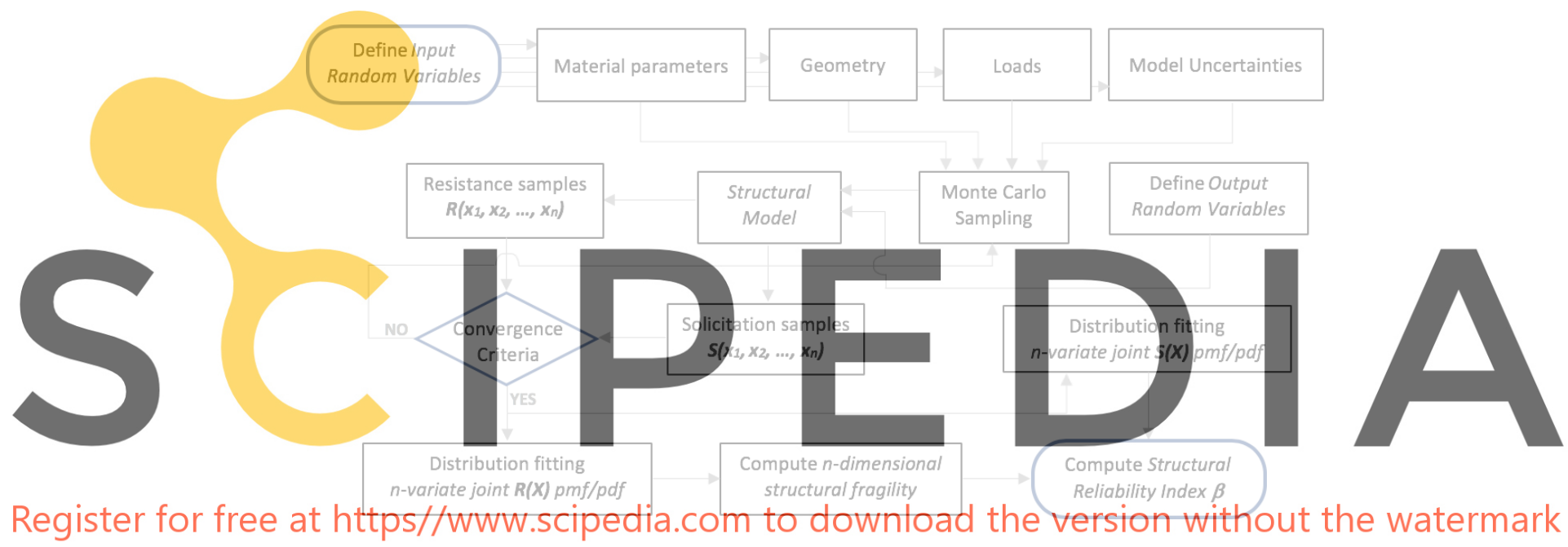

Figure 1. General structural reliability workflow.

Table 1. Properties of the selected EAF concrete categories ( $\left({ }^{\mathrm{a}}\right.$ concrete compressive strength ratio; ${ }^{\mathrm{b}}$ concrete specific weight ratio).

\begin{tabular}{cccc}
\hline & EAF $-\mathrm{C} 1$ & $\mathrm{EAF}-\mathrm{C} 2$ & $\mathrm{EAF}-\mathrm{A}$ \\
\hline EAF aggregates size & $>4 \mathrm{~mm}$ & $>4 \mathrm{~mm}$ & $0-4 \mathrm{~mm}$ \\
\hline $\mathrm{W} / \mathrm{c}$ ratio & $\leq 0.5$ & $>0.5$ & - \\
\hline $\mathrm{f}_{\mathrm{C}_{\text {EAFF }} / \mathrm{f}_{\mathrm{C} \mathrm{NA}}}{ }^{\mathrm{a}}$ & $0.99-1.92$ & $0.79-1.92$ & $0.78-1.11$ \\
\hline$\rho_{c_{\_} \text {EAF }} / \rho_{c_{\_} \mathrm{NA}}{ }^{\mathrm{b}}$ & $1.11-1.24$ & $1.01-1.27$ & $1.01-1.28$ \\
\hline
\end{tabular}




\section{Application to Two Case-Study Bridges}

The abovementioned structural reliability workflow was used to investigate how the use of EAF concretes can impact structural safety of two different common bridge configurations, namely a single-span simply supported PRC girder bridge (Bridge \#1) and a two-span continuous steel/concrete composite I-girder bridge (Bridge \#2). Both bridge types were first designed according to the 2008-Italian Building Code prescriptions (Italian Ministry for Constructions 2008), considering the use of ordinary NA concrete mixes. A reliability analysis was then carried out on the benchmark case (NA) and on the three hypothetical sustainable construction solutions (i.e. the same bridges in terms of sizing and reinforcement), realized with EAF-C1, EAF-C2 and EAF-A concrete mixes. Load analysis was conducted for both structures in accordance to Italian codes, accounting for self-weights of girders, dead loads of guard-rails and parapets, traffic loads, and in addition, taking into account wind actions and RC pier selfweight in Bridge \#2.

\subsection{Bridge \#1: Single-Span Simply-Supported PRC Girder}

The first case study is represented by a single-span simply supported PRC girder bridge. The span is 22 m-length and $13.5-\mathrm{m}$ width and is composed by a RC slab of 30-cm thickness sustained by 7 PRC beams connected with transverse cast-in-situ RC beams (0.2-m x 0.9-m) located at the quarters. Each PRC beam is characterized by a double-T section of $1.3-\mathrm{m}$ height
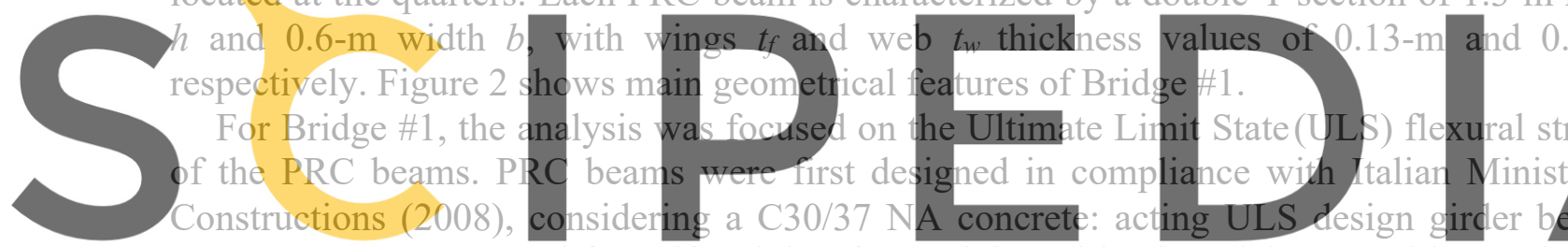

moments were computed for self-weight of materials and load model LM1 with TS placed at

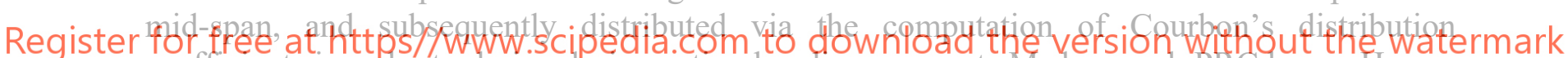
coefficients in order to derive design acting bending moments Msd on each PRC beam. Hence,

PRC beam design was performed considering a stress-block constitutive law for concrete and an elasto-perfectly plastic law for prestressing steel, assuming section wings of constant average thickness equal to $0.165 \mathrm{~m}$, neglecting the contribution of ordinary steel reinforcing bars and considering a resultant prestressing cable ideally condensing all prestressing steel area Ap. Main materials parameters adopted in PRC beam design.

Once designed the most loaded PRC beam, reliability analysis was carried out in order to assess structural safety margin for the same bridge configuration realized both with NAC and the sustainable EAF concrete mixes. First, input random variables were fixed for material parameters, geometrical features, loads and model uncertainties: the type of distribution and coefficient of variation assumed for each random variable can be found in Zanini (2019). One output random variable $\mathrm{x}$ is here monitored, i.e. bending moment at mid-span. $M C$ simulations were run sampling data from input distributions and deriving bending moment solicitation $M_{S}(x)$ and resistance $M_{R}(x)$ samples until the achievement of the convergence criterion. Hence, sampled $M_{S}(x)$ and $M_{R}(x)$ values were fitted in order to derive related pdfs parameters: Figure 3 shows bending moment $M_{S}$ pdfs and $M_{R}$ fragility curves for both NA and EAF concrete mixes, evidencing a lower fragility for EAF-C1 and EAF-C2 classes with respect to NA, whereas 
EAF-A class shows a higher fragility, and this can be mainly attributed to the compressive strength reduction that characterizes EAF-A mix.

a)

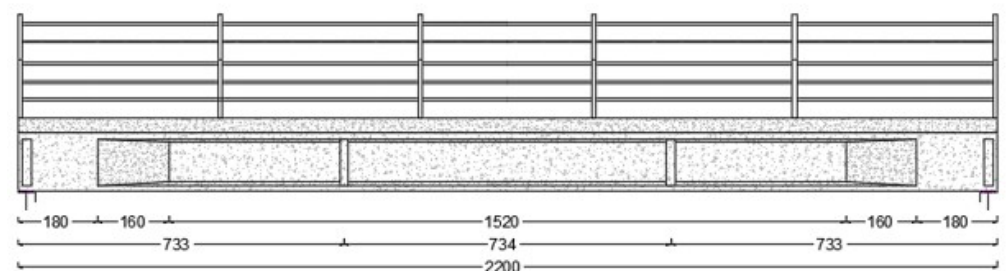

b)
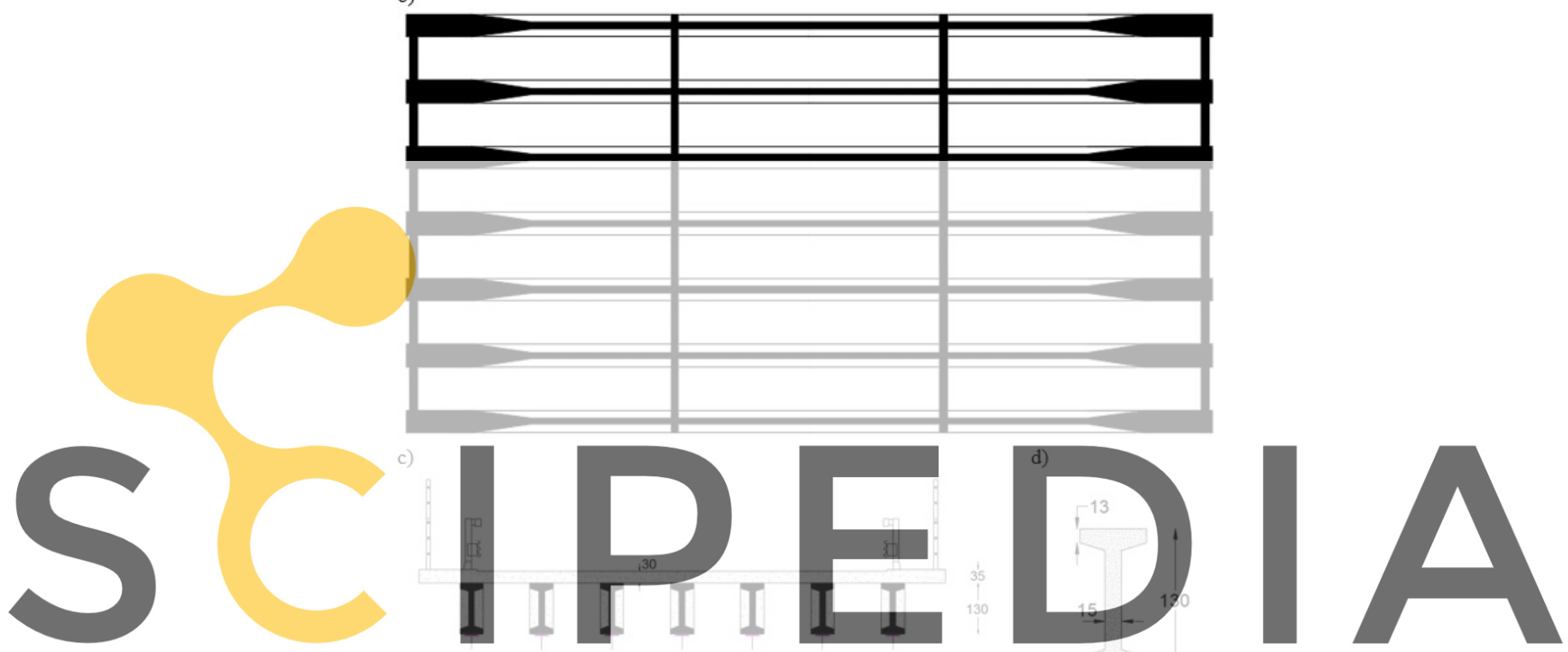

Register for free at https//www.scipedia.com to download the version without the watermark

Figure 2. Bridge \#1 main geometrical characteristics [in cm]: girder profile (a), girder plan (b), deck section (c) and PRC beam section (d).

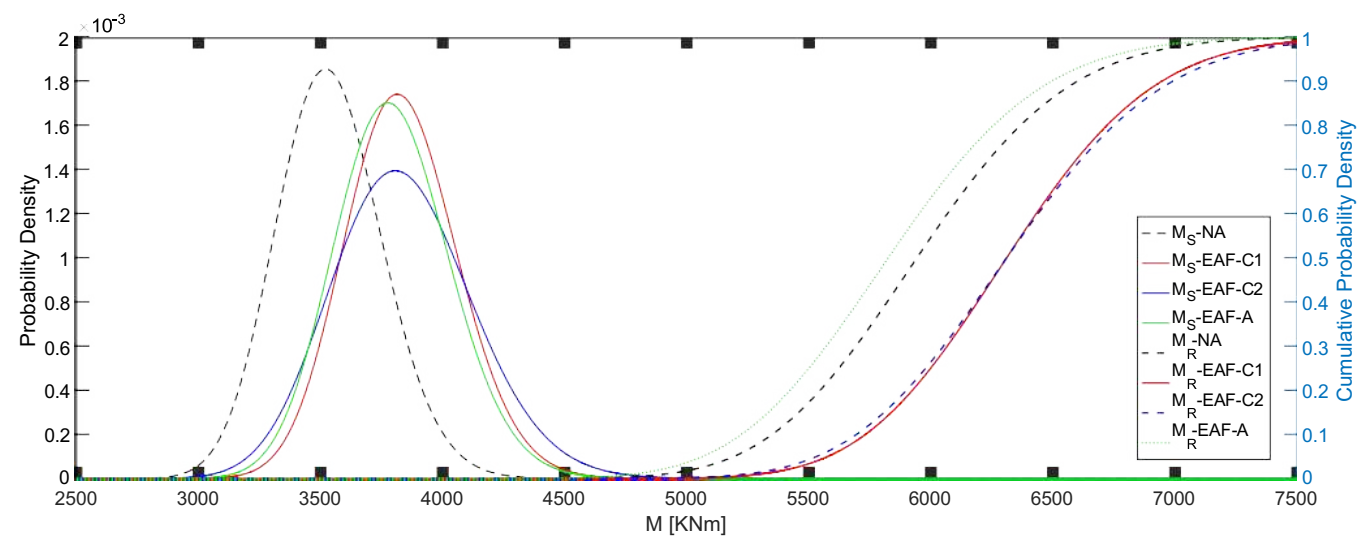

Figure 3. Bridge \#1 bending moment $M_{S} p d f$ s and $M_{R}$ fragility curves for NA and EAF concretes. 
In addition, slight differences can also be observed when comparing bending moment solicitations MS of the three EAF concrete classes, while their pdfs are higher with respect to the NA mix one, mainly due to their higher self-weight. Lastly, failure probabilities $P_{f}$ and related Structural Reliability Index $\beta$ were computed for each concrete mix, leading to $P_{f}$ estimates of $1.98 \mathrm{e}-07,7.24 \mathrm{e}-08,3.48 \mathrm{e}-06,2.28 \mathrm{e}-05$ and $\beta$ values $5.071,5.259,4.495,4.077$ for NA, EAF-C1, EAF-C2 and EAF-A concretes, respectively. Results highlighted how the use of EAF-C1 in this specific application leads to structural safety margins higher than NA concretes, whereas EAF-C2 and EAF-A are characterized by lower structural reliability levels.

\subsection{Bridge \#2: Two-Span Continuous Steel/Concrete Composite I-Girder}

The second case study is represented by a two-span continuous steel/concrete composite Igirder bridge (Figure 4). Bridge \#2 has two spans of $30-\mathrm{m}$ length and $13.5-\mathrm{m}$ width and is composed by a deck consisting in a RC slab of 30-cm thickness supported by 2 I steel profiles of variable height ranging from $1.7-\mathrm{m}$ at abutments to $2.8-\mathrm{m}$ at pier support, connected with open diaphragms made with coupled L steel profiles. I-steel profiles were sized according to the 2008-Italian Building Code prescriptions Italian Ministry for Constructions (2008), thus resulting in steel plates of 40-mm, 60-mm and 30-mm thickness for the upper wing, lower wing and web, with $0.9-\mathrm{m}$ and $1.3-\mathrm{m}$ width for upper and lower wings, respectively. The deck is supported by a $16-\mathrm{m}$ height $\mathrm{RC}$ pier characterized by a rectangular hollow section with $2.5-\mathrm{m}$ height, $1.5-\mathrm{m}$ width and $30-\mathrm{cm}$ thickness. In the upper part, pier has a variable section which

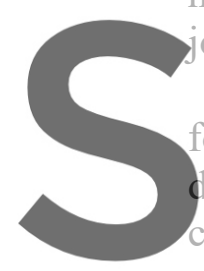
oints with a beam cap of

For Bridge \#2, the and force-bending moment designed according to concrete and a B450C
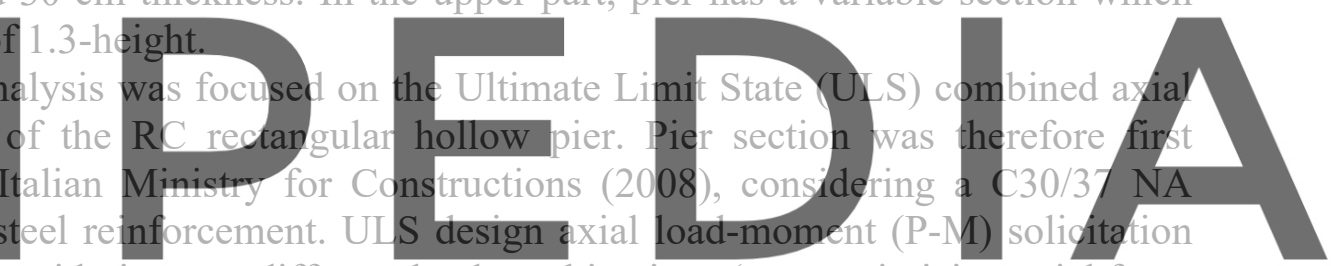

points were computed considering two different load combinations (i.e. maximizing axial force

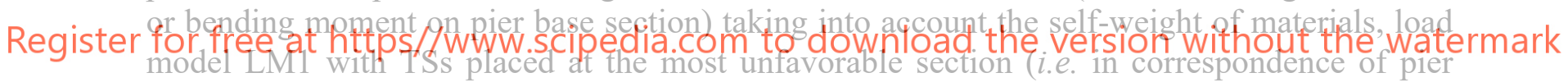
support), and wind action computed with the following formula:

$$
W=\frac{1}{2} \rho v_{b}^{2} c_{p} c_{e} c_{s} A_{r e f}
$$

where $\rho$ is the air mass density equal to $1.25 \mathrm{~kg} / \mathrm{m}^{3}, v_{b}$ is the wind velocity measured at $10 \mathrm{~m}$ above the ground for open-country surface conditions, $c_{p}, c_{e}$ and $c_{s}$ stand for the pressure, exposure and shape coefficients, respectively, and $A_{\text {ref }}$ is the surface area of the structural members impacted by wind. An equivalent rectangular $A_{\text {ref,deck }}$ area of 2.6-m height was considered for deck, also adding a $3-\mathrm{m}$ height equivalent rectangular $A_{\text {ref,traffic }}$ area in order to take into account also vehicles profile, as specified in Italian Ministry for Constructions (2008). P-M solicitation points were derived for both analyzed load combinations and then reinforcing steel area was iteratively derived by computing the resistance P-M interaction diagram, adopting a stress-block constitutive law for concrete and an elasto-perfectly plastic law for reinforcing steel bars with main materials' mechanical properties listed in Zanini (2019). 
Pier design process lead to identify the reinforcement solution able to equalize the worst P$\mathrm{M}$ solicitation point, thus resulting in two layers of $20 \mathrm{~mm}$ diameter longitudinal reinforcement steel bars with $10 \mathrm{~cm}$ spacing (i.e. one inner and one outer surfaces, 28 bars in the shorter RC web and 40 bars in the longer one, see Figure $4 d$ ).

a)
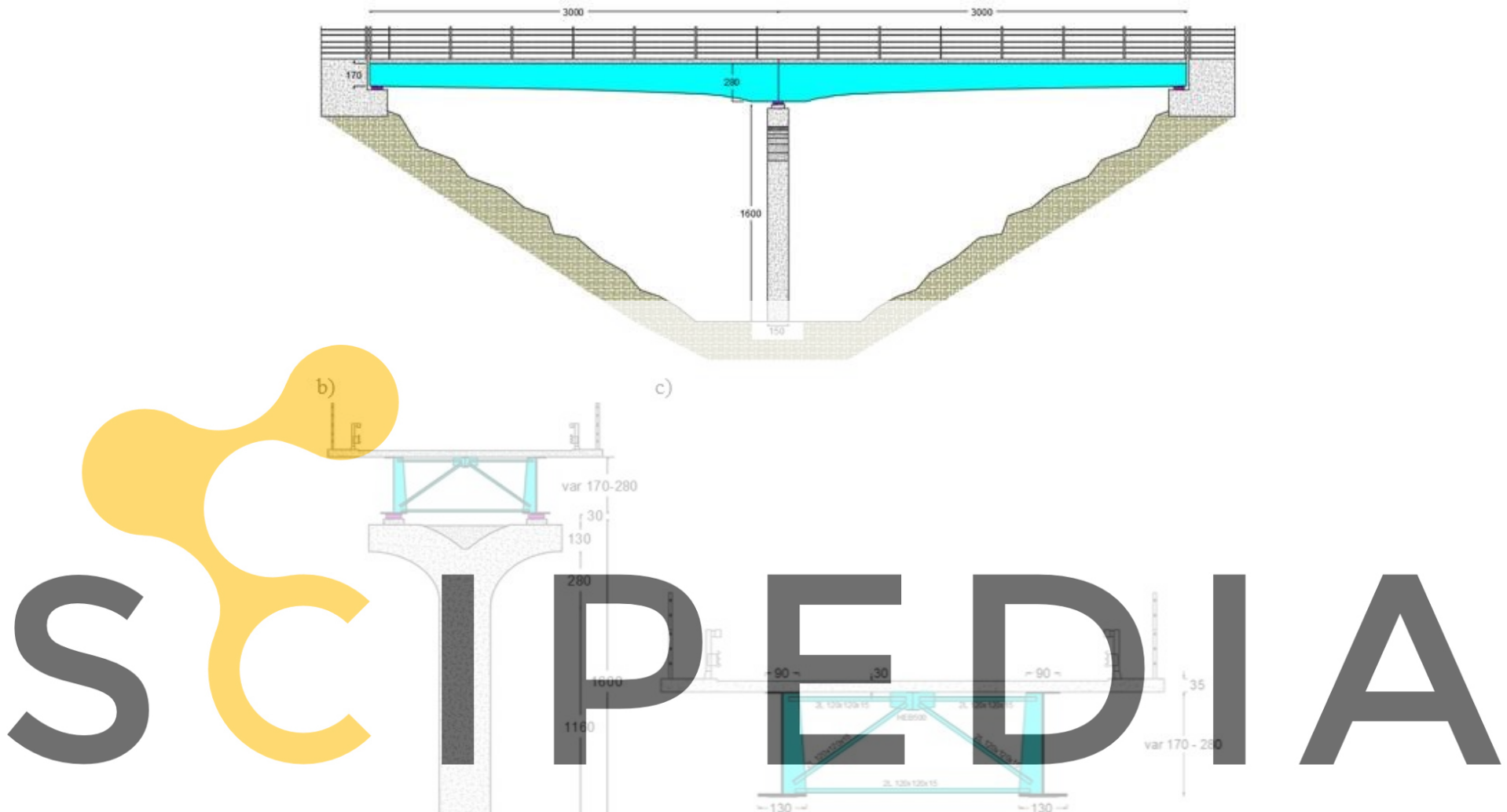

Register for free at https//www.scipedia.com to download the version without the watermark

d)

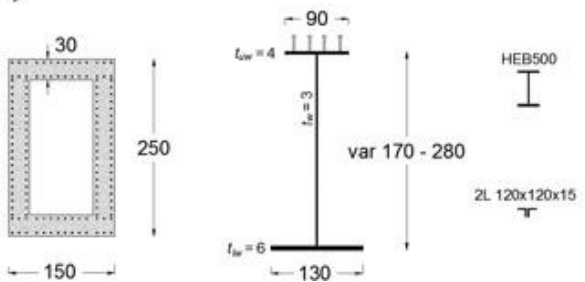

Figure 4. Bridge \#2 main geometrical characteristics [in $\mathrm{cm}]$ : longitudinal profile (a), transversal section (b), deck section (c) and RC rectangular hollow pier and main steel profile sections (d).

Once designed the RC rectangular hollow pier, reliability analysis was carried out in order to assess structural safety margin for the same bridge configuration realized with sustainable EAF concrete mixes both in RC slab and pier elements. Input random variables were fixed, as listed 
in Zanini (2019), whereas in this specific case, two output random variables $x_{1}, x_{2}$ were monitored, i.e. RC pier base section bending moment and axial force. MC simulations were run sampling data from input distributions, and deriving couples of bending moment-axial force solicitation $M_{S}\left(x_{1}\right)-N_{S}\left(x_{2}\right)$ and resistance P-M interaction diagram samples $M_{R}\left(x_{1}\right)-N_{R}\left(x_{2}\right)$ until the achievement of the adopted convergence criteria. Figure 5 represents fragility surfaces derived for both NA and EAF concrete mixes highlighting, as expected, a lower fragility for EAF-C1 and $-\mathrm{C} 2$ classes with respect to EAF-A and NA mixes.

a)
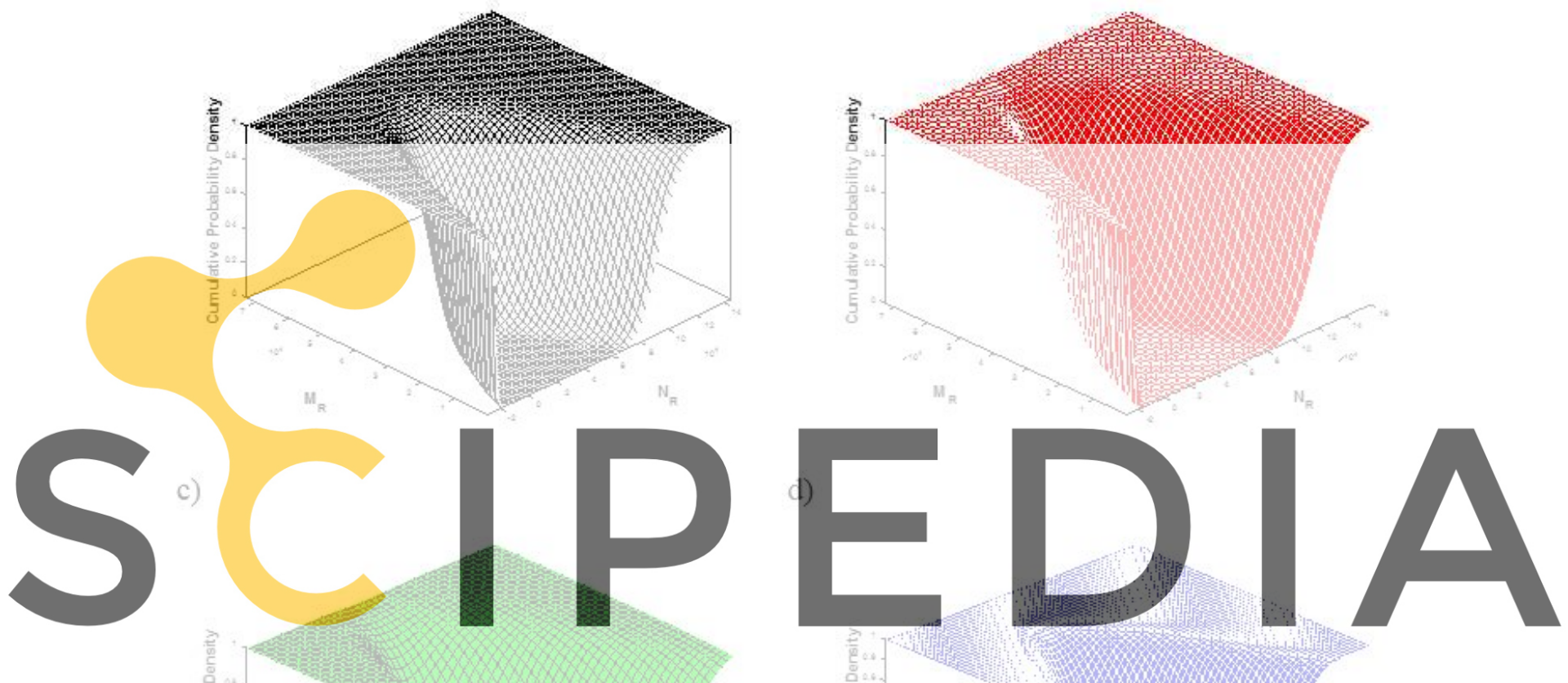

Register for free at https//www.scipedia.com

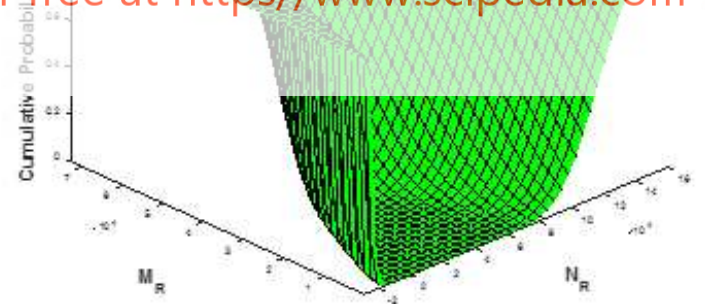

b)
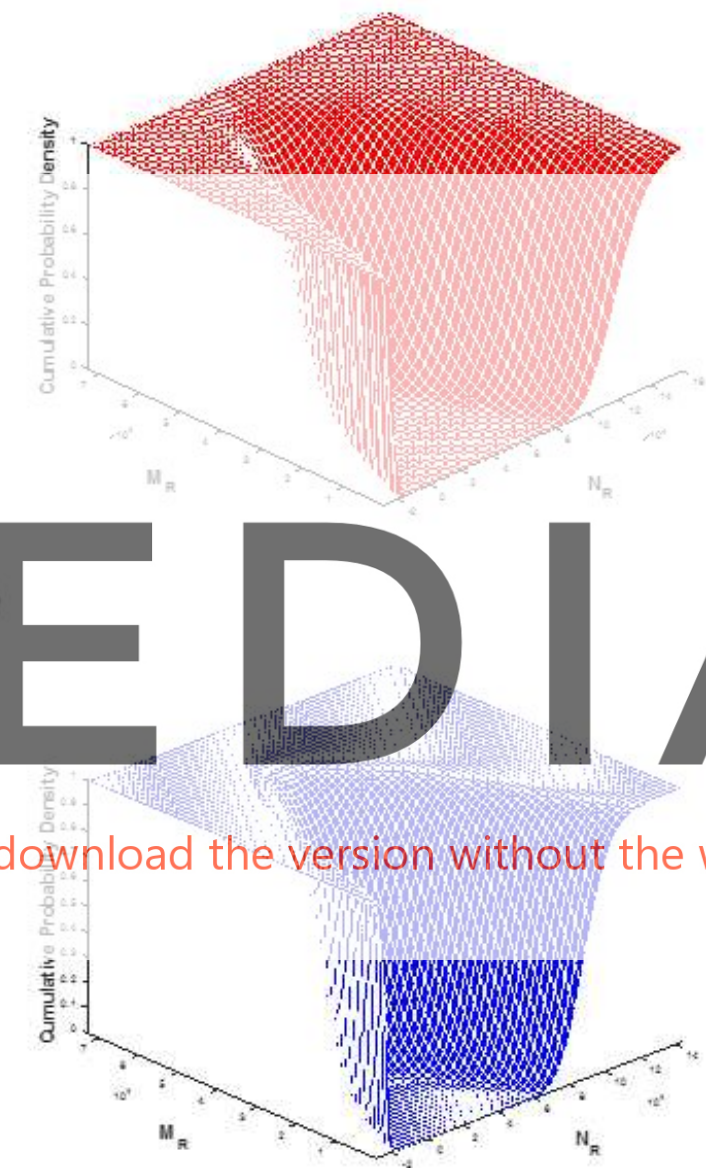

Figure 5. Bridge \#2 joint bivariate fragility surfaces for NA (a), EAF-C1 (b), EAF-C2 (c) and EAF-A (d) concretes.

Failure probabilities $P_{f}$ and related Structural Reliability Index $\beta$ were then computed with Eqs. 1, 4 obtaining $P_{f}$ estimates of $4.25 \mathrm{e}-05,1.26 \mathrm{e}-05,1.93 \mathrm{e}-05,5.53 \mathrm{e}-05$ and $\beta$ values 3.930 , 4.212, 4.116, 3.866 for NA, EAF-C1, EAF-C2 and EAF-A concretes, respectively. Results evidenced how the use of EAF-C1 and - $\mathrm{C} 2$ mixes in this specific application leads to structural safety margins higher than NAC, whereas EAF-A is characterized by lower structural reliability levels. 


\section{Conclusions}

The present work investigated the influence on structural safety margins related to the replacement of common NAC mixes with EAF ones, with special emphasis to the field of the design of common bridge types. A general structural reliability workflow was proposed in order to formalize the methodology to be used in assessing the structural reliability index for a generic n-dimensional problem. Two bridge case studies were then analyzed, showing reliable outcomes when using EAF concretes for structural elements subject to compressional regimes, like bridge piers or PRC beams. Among future improvements of the present study, further efforts will also be required in order to investigate the impact of EAF concretes on seismic reliability of RC structural systems.

\section{ORCID}

Mariano Angelo Zanini: https://orcid.org/0000-0001-9326-802X

References

De Domenico, D., Faleschini, F., Pellegrino, C. and Ricciardi, G. (2018). Structural behavior of RC beams containing EAF slag as recycled aggregate: Numerical versus experimental results. Constr Build Mater, 171, 321-337.

Faleschini, F., Fernández-Ruíz, M.A., Zanini, M.A., Brunelli, K., Pellegrino, C. and Hernández-Montes, E. (2015). High performance concrete with electric arc furnace slag as aggregate: mechanical and durability properties. Constr Build Mater, 101,113-121.

Faleschini, F., Bragolusi, investigation on the cy 347.

Faleschini, F., De Marzi, P. assessment through LCA

Faleschini, F., Hofer, L., Zanini, M.A., Dalla Benetta,
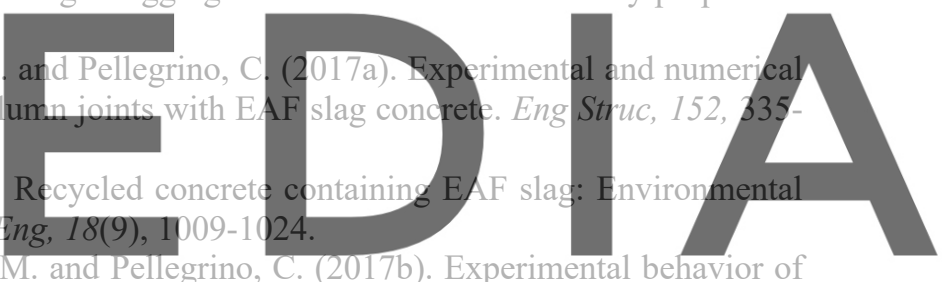
beam- column joints made with EAF concrete under cyclic loading. Eng Struc, 139, 81-95.

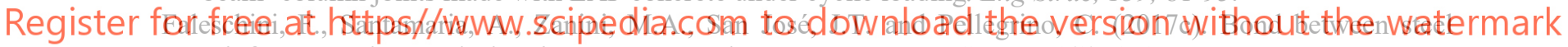
reinforcement bars and Electric Arc Furnace slag concrete. Mater Struct, 50(3), 170.

Geiseler, J. (1996). Use of steelworks slag in Europe. Waste Manage, 16, $59-63$.

Italian Ministry for Constructions (2008). D.M. 14/01/2008, Technical Rules for Constructions, Rome, Italy. (in Italian).

Koros, P.J. (2003). Dusts, scale, slags, sludges... Not wastes, but sources of profits. Metallurgical and Materials Transactions B, 34(6), 769-779.

Motz, H., Geiseler, J. (2001). Products of steel slags an opportunity to save natural resources. Waste Manage, 21(3), 285-293.

Papayianni, I. and Anastasiou, E. (2010). Production of high-strength concrete using high volume of industrial by- products. Constr Build Mater, 24, 1412-1417.

Pellegrino, C., Cavagnis, P., Faleschini, F. and Brunelli, K. (2013). Properties of concretes with Black/Oxidizing Electric Arc Furnace slag aggregate. Cem Concr Compos, 37, 232-240.

Pellegrino, C. and Faleschini, F. (2013). Experimental behavior of reinforced concrete beams with electric arc furnace slag as recycled aggregate. ACI Mater J, 110, 197-206.

Santamaría, A., Orbe, A., Losañez, M.M., Skaf, M., Ortega-Lopez, V., González, J.J. (2017). Self-compacting concrete incorporating electric arc-furnace steelmaking slag as aggregate. Mater Des, 115, 179-193.

Zanini, (2019). Structural reliability of bridges realized with reinforced concretes containing electric arc furnace slag aggregates. Eng Struc, 188, 305-319. 